\title{
The Effect of Low-Temperature Hydrothermal Alteration on the Remanent Magnetization of Synthetic Titanomagnetites: A Case for Acquisition of Chemical Remanent Magnetization
}

\author{
Paul R. Kelso and Subir K. Baneree
}

Institute for Rock Magnetism and Department of Geology and Geophysics, University of Minnesota, Minneapolis

\author{
HORST-ULRICH WORM
}

Federal Institute for Geosciences and Natural Resources, Einbeck-Rotenkirchen, Germany

\begin{abstract}
The effect of hydrothermal alteration on the thermoremanent magnetization (TRM) of synthetic titanomagnetite ( $\mathrm{TM} 40: \mathrm{Fe}_{2.6} \mathrm{Ti}_{0.4} \mathrm{O}_{4}$ ) has been studied, to simulate the alteration that occurs in the oceanic crust. Pseudo-single-domain titanomagnetite grains, similar in size to those often found in oceanic basalts, were dispersed in a permeable but rigid glass matrix. This resulted in a TRM in the sample which was subsequently oxidized in acidic solutions while a magnetic field $(0.1 \mathrm{mT})$ was applied perpendicular to the TRM direction. The experiments were conducted in a non-magnetic stainless steel pressure vessel at $150^{\circ} \mathrm{C}$ in solutions of acidity varying from $p \mathrm{H}=2$ to $p \mathrm{H}=7$. In addition to being time and temperature dependent, the acquired chemical remanent magnetization (CRM) was also found to be very $\mathrm{pH}$ dependent. The degree of maghemitization increased drastically as the acidity of the hydrothermal solution was increased in accordance with a process controlled by the loss of iron ions in aqueous solutions. Long-term storage experiments at carefully chosen temperatures demonstrated that no significant viscous remanent magnetization was acquired during heating. It was found that during the alteration of TM40 to titanomaghemite the CRM is along the ambient field direction from the onset, and not partly or wholly along the TRM direction as has been found in previous air oxidation experiments. This has important implications for the possible cause of anomalous skewness of marine magnetic anomalies and for the anomalous directions of natural remanent magnetization found in some oceanic basalt samples.
\end{abstract}

\section{INTRODUCTION}

The magnetic carrier in pillow basalts changes composition from place to place on the ocean floor, with freshly erupted titanomagnetite having a restricted range in composition that becomes progressively more oxidized as one moves away from the ridge. This observation has spawned considerable debate concerning how oxidation affects the natural remanent magnetization (NRM) of oceanic basalts. There is a well documented decrease in the total NRM by nearly an order of magnitude during the first 20 m.y. after the basalts' emplacement [e.g., Bleil and Petersen, 1983]. More controversial is whether or not a chemical remanent magnetization (CRM) is acquired during the oxidation, and if a CRM is acquired, is it along (1) the original thermal remanent magnetization (TRM) direction (2) the ambient field direction or (3) some intermediate direction? The answer to this question is central to understanding such phenomena as the change in shape and amplitude in marine magnetic anomalies with increased distance from oceanic spreading centers and the origin of anomalous directions in some deep-sea samples (for a review see Johnson, [1979]).

Titanomagnetites in nature often undergo low-temperature $\left(<250^{\circ} \mathrm{C}\right)$ oxidation to form nonstoichiometric, cation-deficient titanomaghemite, which retains the spinel structure of titanomagnetite. This oxidation can proceed by two methods: (1) the addition of oxygen to the lattice or (2) the removal of ferrous iron from the lattice [ $O^{\prime}$ Reilly 1983]. Natural evidence suggests that in oceanic basalts the primary method of oxidation is by the

Copyright 1991 by the American Geophysical Union.

Paper number $91 \mathrm{JB} 01975$

0148-0227/91/91JB-01975\$05.00 removal of iron [e.g., Marshall and Cox, 1972; Grommé and Mankinen, 1976; Ryall and Hall, 1980; Akimoto et al., 1984; Furuta et al., 1985]. The strongest evidence supporting this claim is the observed decrease in the $\mathrm{Fe} / \mathrm{Ti}$ ratio with oxidation in natural samples. The removal of iron mechanism was simulated in our study.

Several studies of the effect of oxidation on the NRM directions in natural samples conclude that the resultant chemical remanent magnetization is acquired along the original TRM direction [Marshall and Cox, 1972; Ryall and Ade-Hall, 1975]. Differences between directions of the oxidized and unoxidized samples have been explained by a viscous remanent magnetization (VRM) acquired by the unoxidized material [Soroka and Beske-Diehl, 1984]. Results of the above studies are not diagnostic with regard to CRM, however, because the ages of most of the pillow basalts were less than 0.7 m.y. Therefore, it is unlikely that the Earth's field direction changed significantly since the time of emplacement and TRM acquisition. Any secondary remanence would be approximately parallel to the TRM, and thus one would not expect the NRM to be deflected significantly during oxidation. BeskeDiehl [1990] performed a more detailed study on the change of magnetization in variably oxidized individual oceanic basalts of a variety of ages. She concluded that when variations in NRM directions existed, they could be explained by a VRM of the lessoxidized course-grained titanomaghemites, although the possibility of a secondary CRM could not be ruled out.

Several previous laboratory experiments have been performed to study the CRM acquisition process, allowing the samples' TRM (or sometimes anhysteretic remanent magnetization) and the ambient field during oxidation to be controlled. Özdemir and Dunlop [1985] oxidized fine-grained (200-500 $\AA$ ) synthetic titanomagnetite in air at elevated temperatures, the ambient field during oxidation 
(i.e., the CRM direction) being perpendicular to the original TRM of the sample. They found that CRM and TRM were parallel up to $z=0.7$, where $\mathrm{z}$, the oxidation parameter, is the proportion of ferrous iron converted to ferric iron, which varies from 0 to 1 . Above $\mathrm{z}=0.7$ the remanence of the sample was deflected away from the TRM direction by $35-40^{\circ}$. They conclude that the CRM is always parallel to the original TRM and that any deflection is caused by a VRM from grains with volumes near the superparamagnetic-single-domain boundary. The direction of this VRM is along the net internal field of the sample, which is a resultant of the TRM and the applied field. A similar experiment performed by Brown and $O^{\prime}$ Reilly [1988] found that little remanence, less than $10 \%$ of the total moment, was acquired along the ambient field during oxidation. A recent study on the oxidation of magnetite to maghemite by Gapeev et al. [1991] has found that a large portion of the remanence acquired along the applied field was actually a VRM that decays with zero field storage. These studies have several limitations in their application to the oxidation of oceanic basalts: (1) experiments were performed on singledomain material, while the typical carrier in oceanic basalts is pseudo-single-domain (PSD); (2) oxidation performed at elevated temperatures greatly increases the contribution of VRM compared to natural processes, where oxidation occurs at approximately $4^{\circ} \mathrm{C} ;(3)$ these results contradict many of the observations from natural samples where a significant remanence, not parallel to the TRM, occurs at $z<0.7$ [e.g., Hall, 1976; Bailey, 1980]; and (4) in these simulations, oxidation occurred by the addition of oxygen method, whereas oxidation in the ocean floor seems to occur by removal of iron.

Worm and Banerjee [1987] performed preliminary experiments on PSD titanomagnetite in an aqueous solution at $90^{\circ} \mathrm{C}$. They found that the CRM acquired during oxidation is along the applied field direction and not parallel to the original TRM. It was this work of Worm and Banerjee that inspired the present study with the goal of circumventing as many as possible of the problems that have plagued earlier studies. A key provision of our study is that oxidation is produced by the removal of iron method, and its principal goal is to determine whether the CRM acquired is along the ambient field during oxidation or is parallel to the original TRM direction.

\section{EXPERIMENTAl Procedure}

\section{Synthesis of Titanomagnetite}

Unoxidized titanomagnetite extruded at oceanic ridges, with an average Curie temperature $\left(\mathrm{T}_{\mathrm{c}}\right)$ of less than $200^{\circ} \mathrm{C}$, would undergo significant thermal demagnetization and viscous remanence acquisition at $150^{\circ} \mathrm{C}$, the temperature at which experiments were performed during this study. This problem was circumvented by using titanomagnetite of composition $\mathrm{Fe}_{2.6} \mathrm{Ti}_{0.4} \mathrm{O}_{4}$ (TM40), which has a Curie temperature of $330^{\circ} \mathrm{C}$. Although this composition is not identical to the majority of natural samples, oxidation of its ferrous ions takes place in a manner similar to that of oceanic basalts; thus interactions and relative contributions of the TRM and the CRM will be similar. A single batch of stoichiometric TM40 was synthesized by thoroughly mixing $13 \mathrm{~g}$ of gamma ferric oxide $\left(\gamma \mathrm{Fe}_{2} \mathrm{O}_{3}\right)$ and $2 \mathrm{~g}$ of titanium dioxide $\left(\mathrm{TiO}_{2}\right)$. The material was pressed into pellets and presintered at $900^{\circ} \mathrm{C}$ for 16.5 hours in a controlled gas flow environment of $\mathrm{CO}_{2} / \mathrm{CO}=5.4$, a slightly reducing atmosphere relative to stoichiometric TM40 [Taylor, 1964; Deines et al., 1974]. After regrinding the material, the main sintering was performed at $1250^{\circ} \mathrm{C}$ for the first hour and at $1350^{\circ} \mathrm{C}$ for the next 5.25 hours. The pellets were quenched in liquid nitrogen $\left(-77^{\circ} \mathrm{K}\right)$ to avoid the possibility of unmixing during cooling. In agreement with earlier observations, the bulk TM40 has a Curie temperature of $330^{\circ} \mathrm{C}$ and a unit cell parameter $\mathrm{a}=$ $8.443 \pm 0.003 \AA$. The latter was obtained from $X$ ray analysis based on 10 different atomic planes.

The TM40 pellets were ground under acetone in an agate mortar and pestle and washed through a $44-\mu \mathrm{m}$ sieve with denatured alcohol. This produced a large grain size distribution with a significant submicron grain tail as seen by scanning electron microscope (SEM) photomicrographs [Kelso, 1990]. A narrower grain size distribution was achieved by acid etching the material for $30 \mathrm{~min}$ in $20 \% \mathrm{HCl}$ to dissolve the fine grain tail. After acid treatment the TM40 was rinsed in water and desiccated. The starting TM40 had a grain size range of $5-40 \mu \mathrm{m}$ with an average size of approximately $20 \mu \mathrm{m}$ determined from SEM photomicrographs. Hysteresis measurements give remanence ratios $\left(\mathrm{J}_{\mathrm{rs}} / \mathrm{J}_{\mathrm{S}}=\right.$ $0.12)$ and coercivity ratios $\left(H_{c r} / H_{c}=2.7\right)$ which are also consistent with PSD material, and thus this TM40 is similar to commonly found natural samples [Lowrie, 1974; Moskowitz and Banerjee, 1981].

\section{Sample Preparation}

The samples consisted of TM40 (5\% by weight) dispersed in an inert matrix of Pyrex. The matrix was prepared by ball milling fragments of Pyrex in water and sieving the slurry to recover a grain size between 40 and $70 \mathrm{~mm}$. TM40 (0.050 g) was hand dispersed in Pyrex $(0.95 \mathrm{~g})$, and the resulting mixture was placed in a $1 \mathrm{~cm}$ by $1 \mathrm{~cm}$ copper cup inside a fused quartz tube with a flowing gas environment of $\mathrm{CO}_{2} / \mathrm{CO}=3$. The quartz tube was held at $725^{\circ} \mathrm{C}$ for $30 \mathrm{~min}$ and then removed from the furnace and quenched in air (while maintaining the $\mathrm{CO}_{2} / \mathrm{CO}$ environment within the tube). This heating process softened the Pyrex enough to form a rigid sample upon cooling, but it did not melt the Pyrex. This produced a very porous and permeable sample through which hydrothermal solutions could flow and thus interact with the TM40, while not disturbing the orientation of the magnetic grains. The samples were given a TRM oriented along their designated $x$ axis in a $0.1-\mathrm{mT}$ (1-Oe) field. Potential oxidation during sample preparation was monitored by performing thermomagnetic measurements at several stages: on the bulk TM40 (before and after acid etching), after sample preparation, after TRM acquisition, and after hydrothermal alteration (i.e., after CRM). The Curie temperature of a sample with a TRM was at most $10^{\circ} \mathrm{C}$ greater than that of the bulk TM40, suggesting that a slight amount of oxidation (<5\%) had taken place prior to the CRM experiment.

\section{Chemical Remanent Magnetization}

The sample was sealed in a Teflon bottle filled with a solution of hydrochloric acid and placed in a nonmagnetic stainless steel pressure vessel. The pressure vessel was partially filled with water, wrapped with a heating element, insulated, and placed in a solenoid inside a three layer mu-metal shield. During the experiments, which were performed at $150^{\circ} \mathrm{C}$, the pressure within the pressure vessel and within the sample bottle remained in equilibrium since they both contained a water-gas interacting system. The sample was oriented in the Teflon bottle such that the coil produced a 0.1-mT(1-Oe) field perpendicular to the original TRM of the sample so that the effect of the TRM on the acquisition of the CRM could be monitored.

After acquisition of the CRM, samples were cooled in two steps to reduce the cooling time and thus oxidation during this phase of the experiment. For the higher-temperature window, $150-120^{\circ} \mathrm{C}$, the sample and pressure vessel were cooled in zero field $( \pm 50 \mathrm{nT})$. 
After reaching $120^{\circ} \mathrm{C}$ the pressure vessel was submerged in ice water $\left(\mathrm{O}^{\circ} \mathrm{C}\right)$ in the ambient laboratory field $(\sim 0.1-\mathrm{mT}$ along the sample's negative $Z$ axis). This resulted in a partial TRM (PTRM) that was on the order of $5-10 \%$ of the total remanent magnetization, as tested by thermal demagnetization. We therefore believe that the observed remanence w as contaminated by a PTRM of no more than $10 \%$ due to the cooling of the vessel.

The $p H$ of the aqueous solution has been shown to have an inverse relationship to the rate of oxidation of titanomagnetite [Worm and Banerjee, 1984; Worm and Banerjee, 1987; D.-W.Suk and S.K. Banerjee, personal communications 1991]; therefore experiments were performed over a $p H$ range from 2 to 7 by varying the concentration of $\mathrm{HCl}$. Geochemical studies of the alteration of oceanic basalts have found that, at high water to rock ratios, $p \mathrm{H}$ 's as low as 2-3 can occur upon initial alteration [e.g., Mottl, 1983; Seyfried, 1987]. Although it is not unreasonable for natural samples to experience $p H$ 's in this range during oxidation, more neutral solutions $(p H \sim 6)$ are probably responsible for the widespread oxidation of the oceanic crust.

The duration of the experiments was varied from a few hours to nearly 2 weeks. The samples were analyzed using alternating field (AF) and thermal demagnetization techniques, saturation magnetization versus temperature curves, $X$ ray diffraction, scanning electron microscopy, and hysteresis properties.

\section{Results ANd Discussion}

\section{Characterization of $C R M$}

Even though greater than $90 \%$ of the TRM had been acquired above the alteration temperature of $150^{\circ} \mathrm{C}$, the possibility of a secondary VRM being acquired by the TM40 during oxidation was a concern. Figure 1 shows the AF demagnetization of a viscous magnetization experiment performed on the unoxidized TM40 at $150^{\circ} \mathrm{C}$ for 141 hours (which is longer than nearly all of the CRM experiments). The fields during TRM and VRM were of the same magnitude $(0.1 \mathrm{mT})$ and perpendicular to each other. There is less than a $10^{\circ}$ offset of the resultant remanent magnetization (Figure 1) from the original (TRM) direction $(+X)$, and upon demagnetization the vector decays straight to the origin. The offset in $Z$ (and part of the $\mathrm{Y}$ ) direction are most likely due to misalignment of the

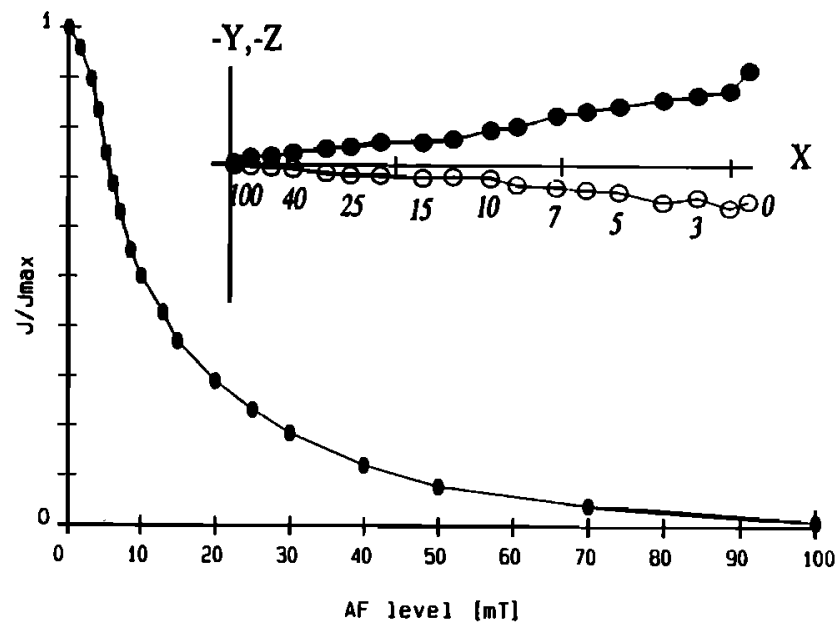

Fig. 1. Zijderveld plot and intensity decay for AF demagnetization of 141 -hour VRM acquired at $150^{\circ} \mathrm{C}$ in $0.1-\mathrm{mT}$ field. The $X,-Y$ plane is represented by filled circles and the $X,-Z$ plane by open circles. The VRM is along the - $Y$ direction, and the original TRM (in $0.1 \mathrm{mT}$ ) is along the $+\mathrm{X}$ direction. sample. The viscous magnetization of the initial TM40, therefore, does not contribute a substantial secondary remanence. The shape of the Zijderveld plot of VRM demagnetization (Figure 1) is also different from the characteristic shape that is observed for CRM demagnetization (Figure 2). Since the unoxidized TM40 does not acquire a significant VRM, the secondary remanence (along $-Z$ ) in Figure 2 is not likely to be a chemicoviscous remanent magnetization (CVRM) of the mother phase, TM40 [Özdemir andD unlop 1989]. On the other hand, our experimental conditions do not allow us to separate clearly the (potential) contribution of a CVRM and a growth CRM of the daughter phase, titanomaghemite, as was done very elegantly in a recent experiment by Gapeev et al. [1991]. Instead, we have concentrated on the direction of the CRM, a matter of great importance to the question of modeling anomalies over altered oceanic crust.

Another component of what we observe as CRM could be a PTRM. However, as discussed in the previous section, the amount of magnetization occurring by cooling from $150^{\circ}$ to $22^{\circ} \mathrm{C}$ was found to be small $(<10 \%)$. Thus it can be concluded that the amount of PTRM acquired during cooling of the samples was minor. Since it has been previously argued that VRM also does not contribute significantly to the NRM, the probable source for the secondary remanence away from the TRM $(+X)$ direction in later experiments is a CRM acquired during the oxidation of TM40. Minor components of magnetization in the $\mathrm{Y}$ direction are most likely due to slight misorientation of the sample.

The AF demagnetization of magnetic remanence after oxidation is displayed in Figure 2, where the TRM is oriented along the positive $X$ axis (i.e., in the horizontal plane, $H$ ) and the ambient field during the CRM is oriented along the negative $Z$ axis. The shape of demagnetization curves is typical of a two-component system where the two vectors are demagnetized simultaneously but at different rates. The model for this demagnetization curve shape is a two-component system with completely overlapping coercivity spectra, but the coercivity spectra have different distributions and peak values [Hoffman and Day, 1978]. The curves displayed in Figure 2 can be interpreted to indicate a component of "inherited" magnetization parallel to the original TRM direction and a second, new component parallel to the direction of the applied field during oxidation. Therefore we conclude that during oxidation the CRM acquired is parallel to the ambient field, which was perpendicular to the TRM. Since complete oxidation was never achieved, the remanence directions in all experiments were intermediate between the TRM and CRM orientations. Similar results have been observed for the inversion of maghemite to hematite [Özdemir and Dunlop, 1988].

Although the TRM and the CRM are not demagnetized completely independently of each other, some generalizations can still be made by examining in detail the AF demagnetization curves (Figure 3) and the shape of the Zijderveld plots (Figure 2). As oxidation proceeds, the coercivity spectrum of AF demagnetization shows that the CRM first becomes more difficult to demagnetize and then becomes easier to demagnetize than the original TRM (Figure 3). It is observed that the component of magnetization parallel to the ambient field during oxidation, i.e., the CRM, is preferentially demagnetized at lower fields, whereas the TRM is the dominant component demagnetized at higher fields. Note, however, that the CRM is not completely demagnetized even after the $100-\mathrm{mT}(1000-\mathrm{Oe})$ demagnetization step. We propose the following hypothesis to explain this behavior.

As oxidation proceeds, microstructural heterogeneity within the initial grains would lead to multiple oxidation fronts proceeding with different velocities. This could lead to stable single- 

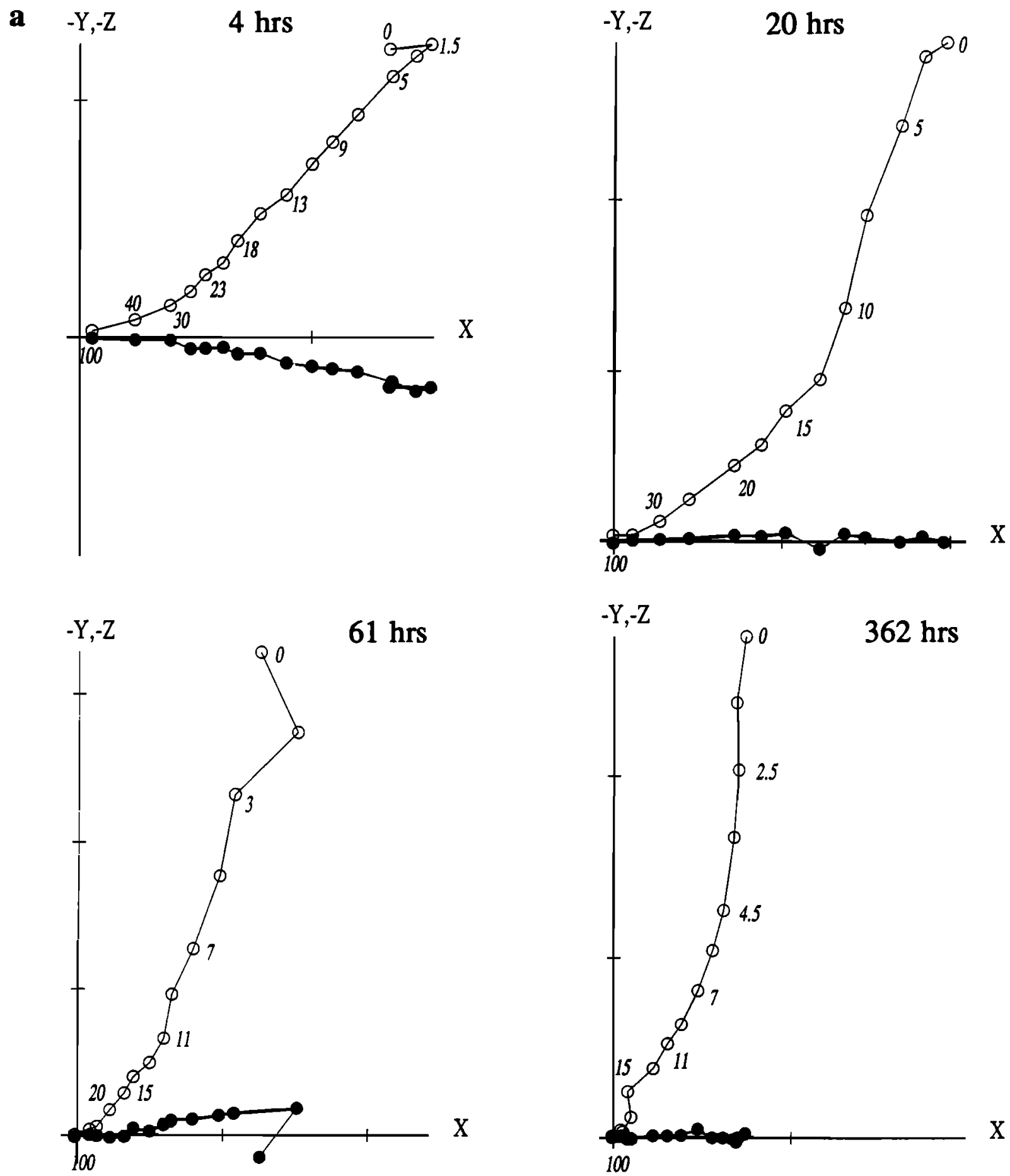

Fig. 2. Zijderveld plots for AF demagnetization of CRM acquired for varying lengths of time in (a) $p H=2$ solution and (b) $p H=3$ solution. The $X,-Y$ plane is represented by filled circles and the $X,-Z$ plane by open circles. The TRM is along the $+X$ axis, and the CRM is along the $-Z$ axis.

domain-like regions within individual grains which were originally pseudo-single domain. Such regions could be the source of the stable CRM component along the applied field, as seen in AF demagnetization. However, in general, the average CRM component is magnetically softer than the remaining TRM component in a given sample.

\section{Effect of pH on CRM Acquisition}

The intensity of CRM acquired increases with increasing oxidation time for a solution of a given $\mathrm{pH}$ (Figure 2). The rate of oxidation, and thus of CRM acquisition, is not a simple linear function but an approximately exponential one (Figure 4), which is dependent on parameters such as grain size, temperature, $p \mathrm{H}$ of the solution, oxygen fugacity, porosity, and permeability. The rate of oxidation increases with decreasing $\mathrm{pH}$ of the oxidizing solution (Figure 5), as has been observed previously [Worm and Banerjee, 1984; D.-W. Suk and S.K. Banerjee, personal communications 1991]. The proposed reaction for the oxidation of titenomagnetite to titanomaghemite in this study is that suggested by Worm and Banerjee [1984]: 
b
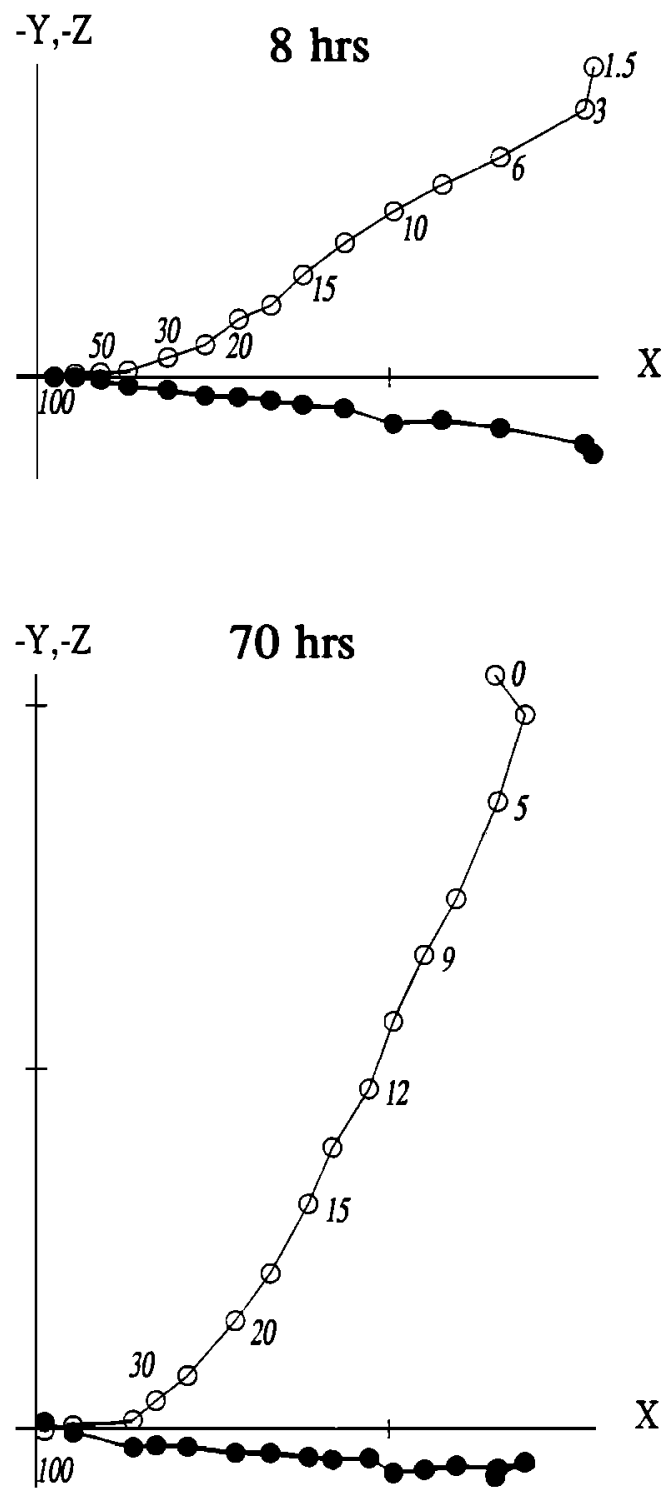

X

Fig. 2. (continued)
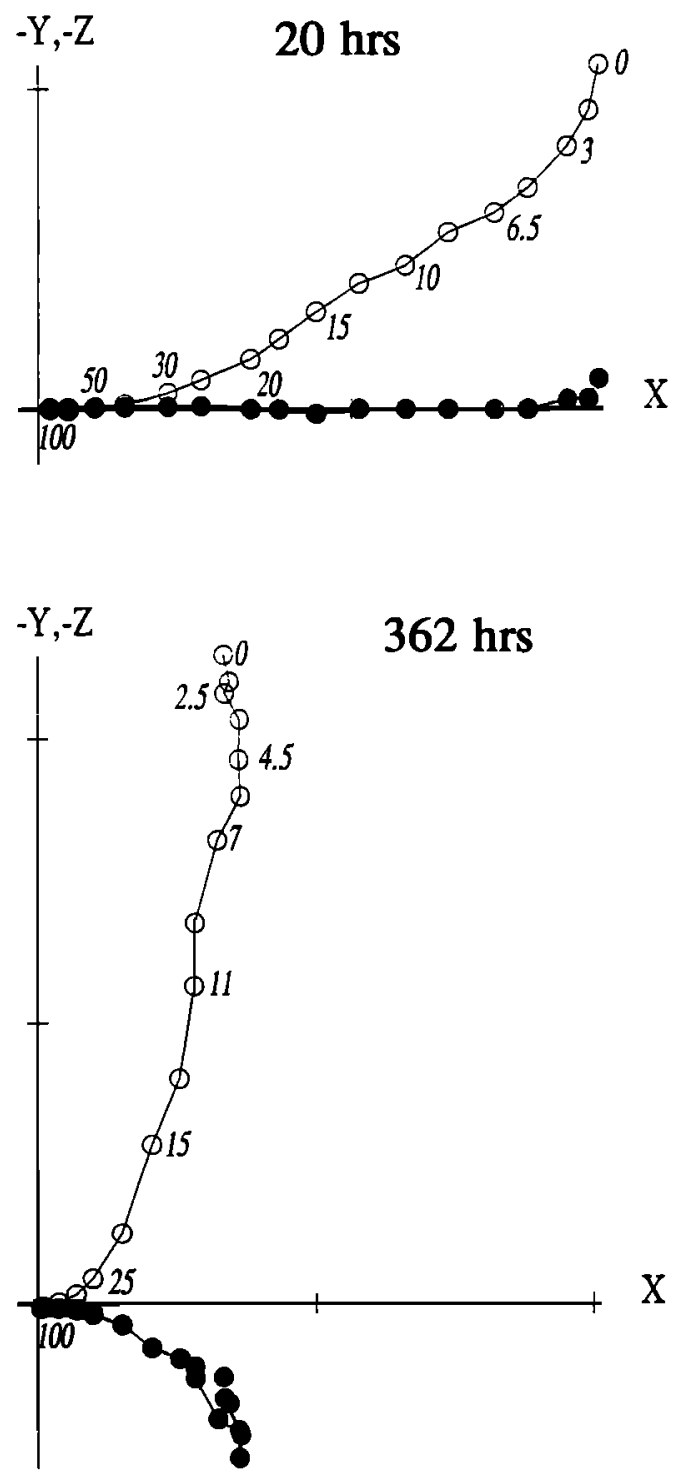

(1)

$$
2 \mathrm{Fe}_{2-2 x+y}^{3+} \mathrm{Fe}_{1+x-(3 y / 2)}^{2+} \mathrm{Ti}_{x} \square_{y / 2} \mathrm{O}_{4}+\mathrm{y} \mathrm{Fe}^{2+}+\mathrm{yH}_{2}
$$

where $\mathrm{x}$ refers to the titanium content in the titanomagnetite, represents vacancies in the titanomaghemite lattice, and $y$ is the amount of ferrous iron converted to ferric iron (note also that some ferrous iron migrates out of the lattice). The gas in the top of the sample bottle after an oxidation run was analyzed using a gas chromatograph and found to contain abundant hydrogen, as predicted by equation (1). A quantitative determination of the amount of hydrogen released during the experiment could not be made because the sample bottle was made of Teflon, which is not completely impermeable to hydrogen gas.

The $p \mathrm{H}=2$ solution produced the highest rate of oxidation, and by 70 hours the CRM's of the samples were starting to approach equilibrium (Figures $2 \mathrm{a}$ and 4 ). The oxidation rate is slower at higher $p H$ 's, where the oxidation continued for much longer times (Figure 5). A significant amount of secondary remanence (i.e., a CRM) is acquired even at very small degrees of oxidation, and this
CRM appears to be parallel to the ambient field. This result is unlike that found by Özdemir and Dunlop [1985] in air oxidation experiments, where CRM was parallel to the TRM except at high degrees of oxidation, where it was along a direction intermediate between the TRM and the ambient field during oxidation.

The amount of oxidation was monitored indirectly by measuring the Curie temperature and lattice parameter of the oxidized sample. The former increases and the latter decreases upon increased oxidation. Direct determination of oxidation is difficult because the conventional analytical methods used often produce additional oxidation themselves. The $X$ ray powder diffraction patterns (on magnetic separates) and curves of sanuration magnetization versus temperature $\left(\mathrm{J}_{\mathrm{S}}\right.$ versus $\mathrm{T}$ ) from experiments run in $p H=2$ and $p H=3$ solution are shown in Figures 6 and 7 , respectively. After oxidation in a $\mathrm{pH}=3$ solution the $\mathrm{X}$ ray peaks are distinct and relatively sharp (Figure 6a). They are representative of classic single-phase, homogeneous oxidation. The double $\mathrm{X}$ ray peaks evident with oxidation in a $\mathrm{pH}=2$ solution (Figure $6 \mathrm{~b}$ ) are typical of inhomogeneous oxidation. In this case there is probably an oxidized rim and a less oxidized core. Both types of 
oxidation, homogeneous and inhomogeneous, are routinely found in samples from the ocean floor [Akimoto et al., 1984; Petersen and Vali, 1987; Bina and Prévot, 1989; Beske-Diehl, 1990]. The $\mathrm{Zijderveld} \mathrm{plots} \mathrm{of} \mathrm{the} \mathrm{two} \mathrm{samples} \mathrm{represented} \mathrm{in} \mathrm{Figure} 6$ have the same characteristic shape displayed in Figure 2. Thus, whether the oxidation is homogeneous or inhomogeneous, their resulting magnetizations can be explained by the same two-component system described earlier. The probable cause of the inhomogeneous oxidation observed in Figure $6 \mathrm{~b}$ is that, due to the low $p \mathrm{H}$ of the

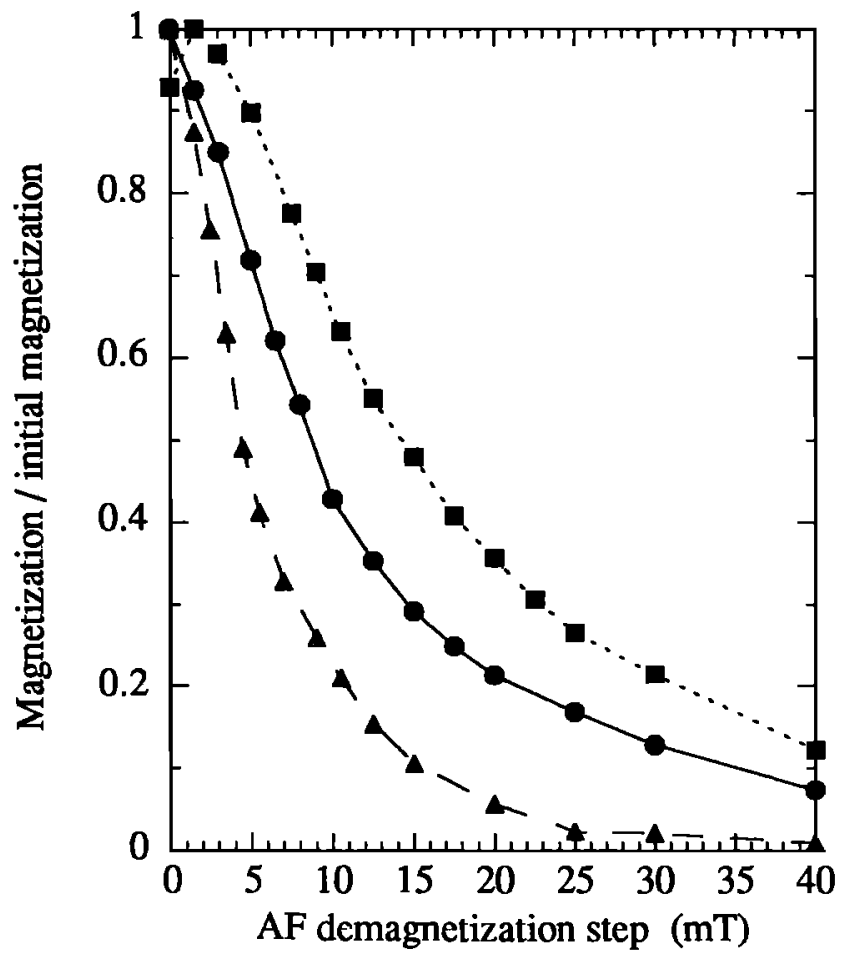

Fig. 3. Altemating field demagnetization spectra for the TRM of the original titanomagnetite (circles) and after oxidation in a $p \mathrm{H}=2$ solution for 4 hours (squares) and 362 hours (triangles), showing first an increase and then a decrease in the coercivity spectrum with oxidation compared to that of the original TRM.

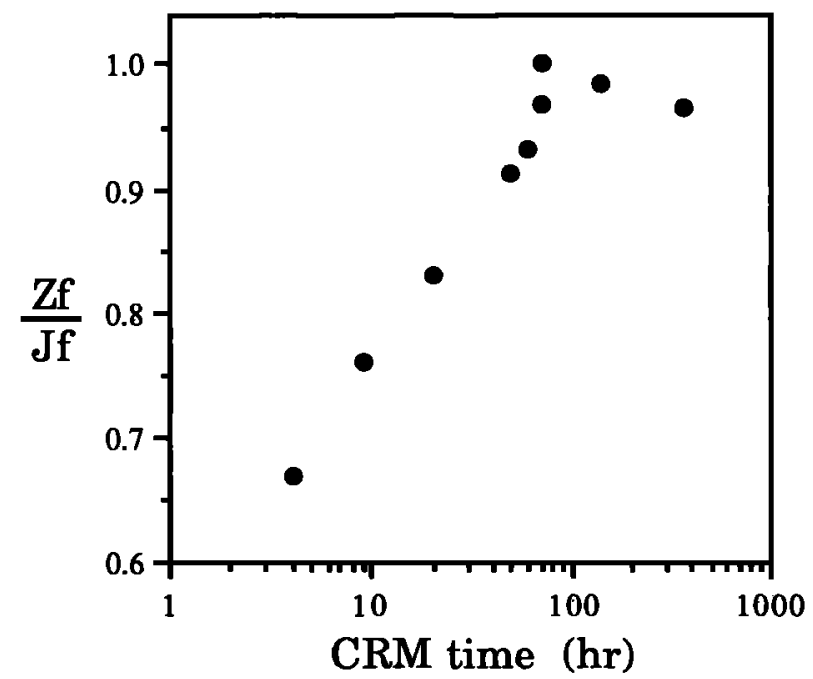

Fig. 4. The variation of $C R M$ acquisition with time in $p H=2$ solutions on a semilog plot, showing an approximately linear increase in the CRM (Zf) relative to the total magnetization (Jf) until oxidation nears completion at approximately $\mathbf{7 0}$ hours. oxidizing solution, the rate of iron removal from the surface of the titanomagnetite was greater than the rate of iron diffusion within the titanomagnetite grain. This would produce a grain with a more oxidized rim and a less oxidized core as has been observed in
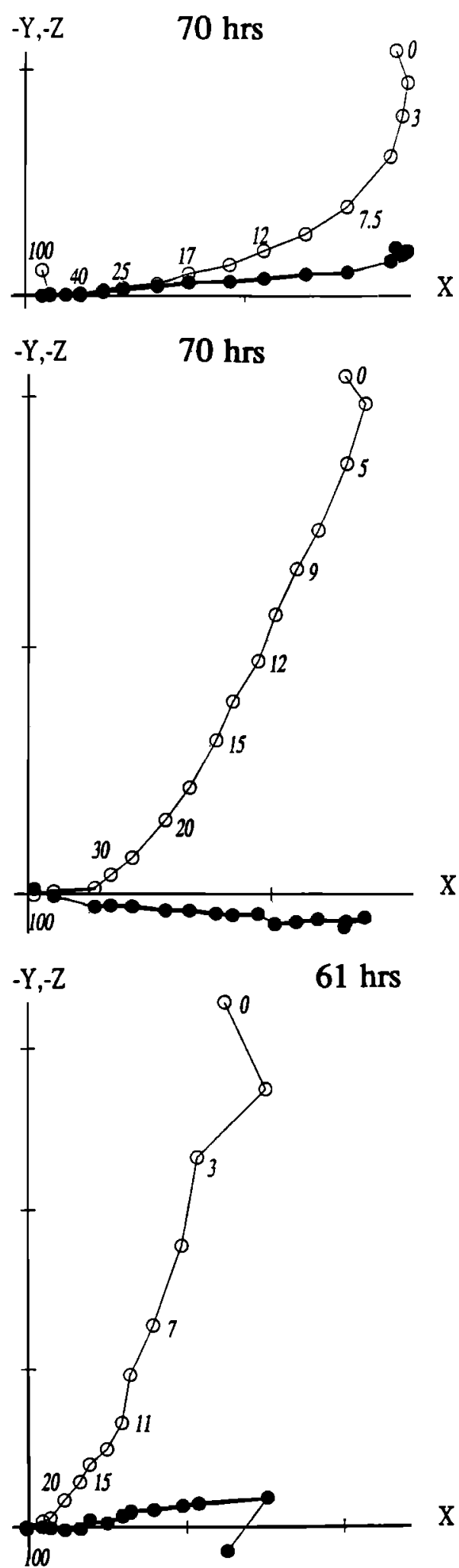

Fig. 5. CRM for similar times in solutions of varying $p H$. CRM increases as $p H$ decreases. The $X,-Y$ plane is represented by filled circles and the $X,-Z$ plane by open circles. The TRM is along the $+X$ axis, and the $C R M$ is along the $-Z$ axis. 

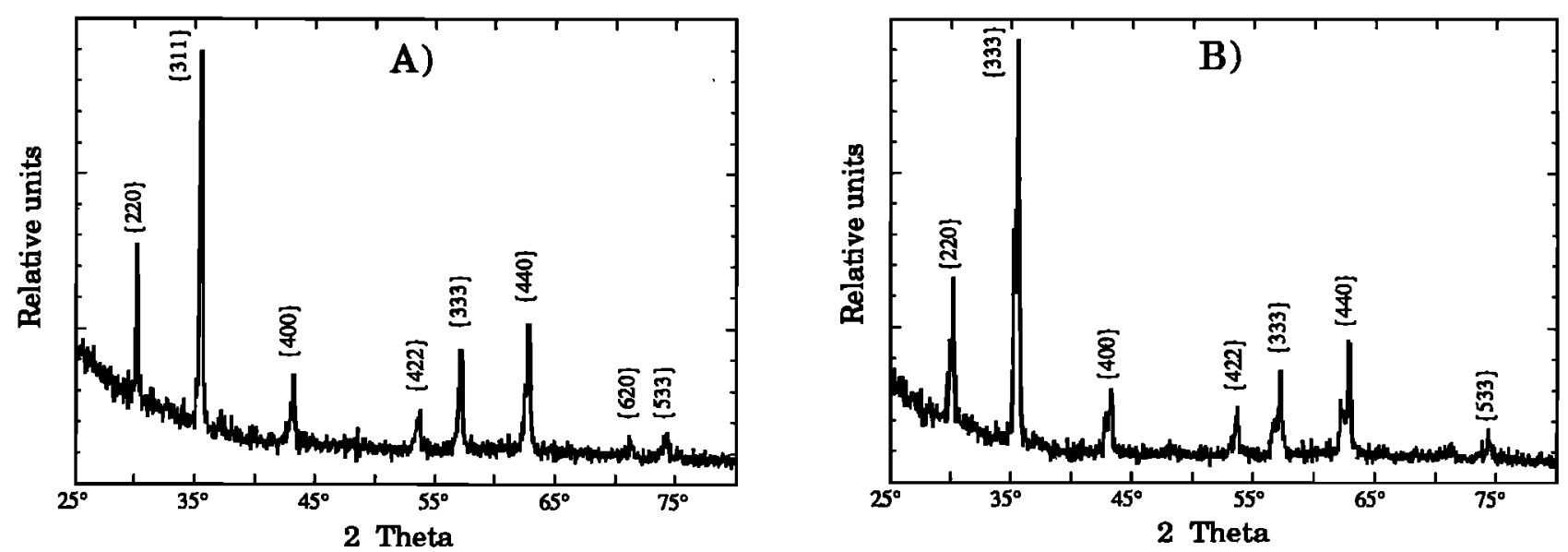

Fig. 6. Powdered $X$ ray diffraction patters for $C R M$ in (a) $p H=3$ solution for 70 hours $(a=8.369 \AA)$ and (b) $p H=2$ solution for 20 hours. Double peaks in part (b) probably indicate an oxidized shell $(a=8.373 \AA$ ) and a less oxidized core $(a=8.430 \AA)$.
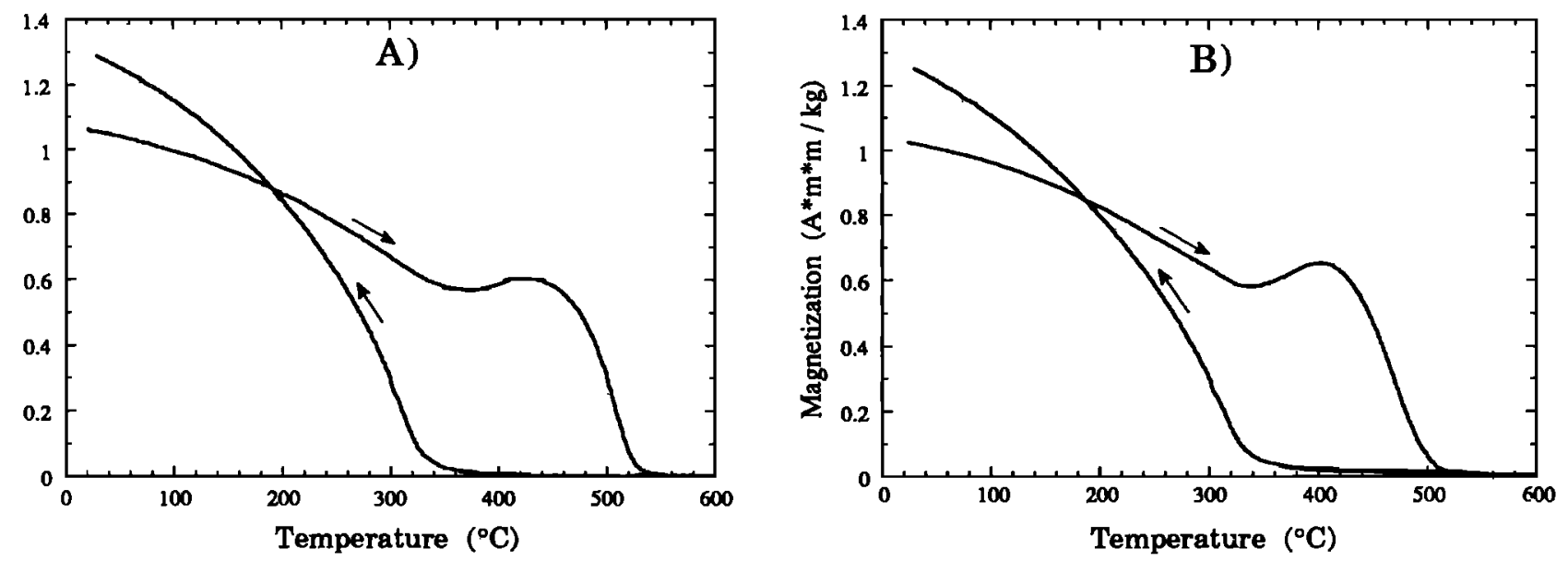

Fig. 7. Js versus $\mathrm{T}$ curves after oxidation for (a) $p H=3$ solution for 70 hours and (b) $p H=2$ solution for 20 hours. Same samples whose $X$ ray diffraction patterns are shown in Figure 6. The relatively low Curie temperature of the cooling leg is most likely due to rehomogenization of titanomagnetite during the thermomagnetic run.

natural samples by Furuta et al., [1985]. There is no evidence of a rhombohedral phase being produced during either type of oxidation as determined from the $\mathrm{X}$ ray diffraction spectra (Figure 6 ) and $J_{S}$ versus $T$ curves (Figure 7 ).

The use of $\mathrm{J}_{\mathrm{S}}$ versus $\mathrm{T}$ curves to determine the relative amount of oxidation of individual samples is somewhat problematic for these low titanium samples, because the inversion temperature of the titanomaghemite is too close to the Curie temperature of the converted titanomagnetite to resolve the $\mathrm{T}_{\mathrm{c}}$ of the titanomaghemite (Figure 7). The $\mathrm{J}_{\mathrm{S}}$ versus $\mathrm{T}$ curves were performed in helium to facilitate heat transfer, after the sample and chamber had been evacuated multiple times to remove all free oxygen. An interesting observation from the $\mathrm{J}_{\mathbf{S}}$ versus $T$ curves of the oxidized material is that the Curie temperature of the cooling leg is very similar to the Curie temperature of the original TM40. The Curie temperature of the cooling leg of most highly oxidized samples from the ocean floor and air oxidation studies is close to that of relatively pure magnetite $\left(\mathrm{T}_{\mathrm{c}}=580^{\circ} \mathrm{C}\right)$. However, low Curie temperature cooling legs have been observed in some studies on natural and synthetic samples (e.g., Marshall, 1978; Hamanoet al., 1980; Nishitani and Kono, 1983; Pechersky et al., 1983; Furuta, 1983; Brown and O'Reilly, 1987; Beske-Diehl, 1990]. The X ray diffraction pattern of one sample was measured after heating to $600^{\circ} \mathrm{C}$, and it was found to have a unit cell dimension of $8.449 \AA$, which is only slightly larger than that of the starting titanomagnetite $(a=8.443$ $\AA)$. One possible explanation is reduction and then rehomogenization of the iron and titanium in the titanomagnetite during $\mathrm{J}_{\mathrm{s}}$ versus $\mathrm{T}$ measurements, as opposed to the formation of exsolution lamellae of magnetite and ilmenite [Hamano et al., 1980; Pertsev and Boronikhin, 1983; Furuta, 1983]. The slight increase in the unit cell parameter is likely due to the final titanomagnetite being more titanium-rich than the starting titanomagnetite because some of the iron migrated out of the lattice.

\section{Conclusions}

This is the first detailed study demonstrating that a chemical remanent magnetization can be acquired during the aqueous oxidation of titanomagnetites by iron removal - the same process by which the oxidation of oceanic basalts proceeds. The CRM is acquired along the ambient field direction during oxidation, and this occurs from the onset of oxidation (i.e., there is no coupling of the CRM and the TRM). Since complete oxidation was never 
achieved, the NRM always retained some memory of the TRM. The rate of oxidation was found to be $\mathrm{pH}$-dependent as has been shown by others [Worm and Banerjee, 1984; D.-W. Suk and S.K. Banerjee, personal communication 1991]. The amount of CRM acquired varies inversely with the $p H$ of the oxidizing solution. The reaction was also found to produce nascent hydrogen gas and thus supports the chemical equation for titanomagnetite oxidation proposed by Worm and Banerjee [1984]. During the oxidation of titanomagnetites there is a decrease in the unit cell parameter, which can lead to cracking of the titanomagnetite grains, both of which have been observed in samples from this study [Kelso, 1990] and in natural titanomagnetites from the ocean floor [AdeHall et al., 1976; Johnson and Hall, 1978; Petersen and Vali, 1987]. Cracking will affect a grain's magnetic stability, and thus it may influence the magnitude of the CRM acquired during oxidation, but cracking should not alter the direction along which a CRM is acquired.

These results have significant implications for the interpretation of marine magnetic anomalies and for paleomagnetic data from oceanic basalts. Assuming that the mechanism of oxidation of submarine basalts is similar to that of this study, then our results can be used to help explain several observations in marine magnetic data. For example, the anomalous NRM directions observed in some oceanic basalt cores may be due to a CRM of the type described above. Additionally, various authors [Raymond and LaBrecque, 1987; Arkani-Hamed, 1989; Arkani-Hamed, 1990; Verhoef and Arkani-Hamed, 1990] have suggested that a CRM and/or VRM acquired along the ambient field direction during the first 20 Ma years after oceanic crust formation may (1) contribute to the anomalous skewness observed in many marine magnetic anomalies and (2) lead to a modulation of the amplitude of marine magnetic anomalies of Mesozoic age. Our study suggests that a CRM due to aqueous oxidation (titanomaghemitization) is a viable mechanism for the oceanic crust and should be incorporated in anomaly modeling in the future.

Acknowledgments. We thank Sue Beske-Diehl and Sue Halgedahl for helpful reviews and comments, and also comments from an anonymous reviewer and Ozden Ozdemir. Contribution 9103 of the Institute for Rock Magnetism, University of Minnesota. Research was funded by NSF grants EAR-8804853 and 8921622, and NASA grant NGT-50421 .

\section{REFERENCES}

Ade-Hall, J. M., H. P. Johnson, and P. J. C. Ryall, Rock magnetism of basalts, Leg 34, Initial Rep. Deep Sea Drill. Proj., 34, 459-468, 1976.

Akimoto, T., H. Kinoshita, and T. Funuta, Electron probe microanalysis on processes of low-temperature oxidation of titanomagnetile, Earth Planet. Sci. Lett., 71, 263-278, 1984.

Arkani-Hamed, J., Thermoviscous remanent magnetization of oceanic lithosphere inferred from its thermal evolution, J. Geophys. Res., 94, $17,421-17,436,1989$.

Arkani-Hamed, J., Magnetization of the oceanic crust beneath the Labrador Sea, J. Geophys. Res, 95, 7101-7110, 1990.

Bailey, M. E., Magnetic properties of deep-ocean basalts, Ph.D. dissertation, University of Toronto, Ont., Canada,1980.

Beske-Diehl, S. J., Magnetization during low-temperature oxidation of seafloor basalts: No large-scale chemical remagnetization, J. Geophys. Res., 95, 21,413-21,432, 1990.

Bina, M. M., and M. Prévot, Thermomagnetic investigations of titanomagnetite in submarine basalts: Evidence for differential maghemitization, Phys. Earth Planet. Inter., 54, 169-179, 1989.

Bleil, U., and N. Petersen, Variations in the magnetization intensity and low-temperature titanomagnetite oxidation of ocean floor basalts, Nature, 301, 384-388, 1983.

Brown, K., and W. O'Reilly, Aqueous maghemitization of titanomagnetite, J. Geophys., 61, 82-89, 1987.

Brown, K., and W. O'Reilly, The effect of low temperature oxidation on the remanence of TRM-carrying titanomagnetite $\mathrm{Fe}_{2.4} \mathrm{Ti}_{0.6} \mathrm{O}_{4}, P$ hys. Earth Planet. Inter., 52, 108-116, 1988.

Deines, P., R. H. Mafziger, G. C. Ulmer, and I. Woermann, Temperatureoxygen fugacity tables for selected gas mixtures in the system C-H-O at one atmosphere total pressure, Bull. Earth Min. Sci. Exp. Sta., no. 88, Penn State University, University Park, 1974.

Furuta, T., Magnetic properties of basalt samples from holes 504B and 505B of the Costa Rica Rift, Deep Sea Drilling Project legs 69 and 70. Initial Rep. Deep Sea Drill. Proj., 69, 711-720, 1983.

Furuta, T., M. Otsuki, and T. Akimoto, Quantitative electron probe microanalysis of oxygen in titanomagnetites with implications for oxidation processes, J. Geophys. Res., 90, 3145-3150, 1985.

Gapeev, A. K., S. K. Gribov, D. J. Dunlop, O. Ozdemir, and V. P. Shcherbakov, A direct comparison of the properties of CRM and VRM in the low-temperature oxidation of magnetites, Geophys. J. Int., 105, 407-418, 1991.

Gromme, S., and E. Mankinen, Natural remanent magnetization, magnetic properties, and oxidation of titanomagnetites in basaltic rocks from DSDP Leg 34, Initial Rep. Deep Sea Drill. Proj., 34, 485-494, 1976.

Hall, J. M., Major problems regarding the magnetization of oceanic crustal layer 2, J. Geophys. Res., 81, 4223-4231, 1976.

Hamano, Y., T. Nishitani, and M. Kono, Magnetic properties of basalt samples from Deep Sea Drilling Project holes 417D and 418A, Initial Rep. Deep Sea Drill. Proj., legs 51, 52, 53, (part 2), 1391-1405, 1980.

Hoffman, K. A., and R. Day, Separation on multicomponent NRM: A general method, Earth Planet. Sci. Lett., 40, 433-438, 1978.

Johnson, H. P., Magnetization of the oceanic crust, Rev. Geophys., 17, 215-226, 1979.

Johnson, H. P., and J. M. Hall, A detailed rock magnetic and opaque mineralogy study of the basalts from the Nazca plate, Geophys. J. $R$. Astron. Soc., 52, 45-64, 1978.

Kelso, P., An experimental study on the effect of low temperature hydrothermal alteration on the magnetization of titanomagnetites, M.S. dissertation, University of Minnesota, Minneapolis, 1990.

Lowrie, W.,Oceanic basalt magnetic properties and the Vine and Matthews hypothesis, Geophys. J., 40, 513-536, 1974.

Marshall, M., The magnetic properties of some DSDP basalts from the North Pacific and inferences for Pacific plate tectonics, J. Geophys. Res., 83, 289-308, 1978.

Marshall, M., and A. Cox, Magnetic changes in pillow basalt due to sea floor weathering, Geophys. J., 77, 6459-6469, 1972.

Moskowitz, B. M., and S. K. Banerjee, A comparison of the magnetic properties of synthetic titanomaghemites and some oceanic basalts, $J$. Geophys. Res., 86, 11,869-11,882, 1981.

Mottl, M. J., Metabasalts, axial hot springs, and the structure of hydrothermal systems at mid-ocean ridges, Geol. Soc. Am. Bull., 94, 161-180, 1983.

Nishitani, T., and M. Kono, Curie temperature and latice constants of oxidized titanomagnetite, Geophys. J. R. Astron. Soc., 74, 585-600, 1983.

O'Reilly, W., The identification of titanomagnetites: Model mechanism for the maghemitization and inversion process and their magnetic consequences, Phys. Earth Planet. Inter., 31, 65-76, 1983.

Ozdemir, O., and D. J. Dunlop, An experimental study of chemical remanent magnetization of synthetic monodomain titanomaghemites with initial thermoremanent magnetization, J. Geophys. Res., 90, $11,513-11,523,1985$.

Ozdemir, O., and D. J. Dunlop, Crystallization remanent magnetization during the transformation of maghemite to hematite, J. Geophys. Res., 93, 6530-6544, 1988.

Ozdemir, O., and D. J. Dunlop, Chemico-viscous remanent magnetization in the $\mathrm{Fe}_{3} \mathrm{O}_{4}-\gamma \mathrm{Fe}_{2} \mathrm{O}_{3}$ system, Science, 243, 1043-1047, 1989.

Pechersky, D. M., L. V. Tikhonov, and B. P. Zolotarev, Rock magnetism and paleomagnetism of basalts drilled during Deep Sea Drilling Project leg 65, Initial Rep. Deep Sea Drill. Proj., 65, 717-726, 1983.

Pertsev, N. N., and V. A. Boronikhin, Alteration zones near veins in basalts, Deep Sea Drilling Project sites 501/504 and 505, Costa Rica Rift, Initial Rep. Deep Sea Drill. Proj., 69, 565-572, 1983.

Petersen, N., and H. Vali, Observation of shrinkage cracks in ocean floor titanomagnetite, Phys. Earth Planet. Inter., 46, 197-205, 1987.

Raymond, C., and J. L. LaBrecque, Magnetization of the oceanic crust: Thermoremanent magnetization or chemical remanent magnetization?, J. Geophys. Res., 92, 8077-8088, 1987.

Ryall, P. J. C., and J. M. Ade-Hall, Radial variation of magnetic properties in submarine pillow basalts, Can. J. Earth Sci., 12, 1959-1969, 1975.

Ryall, P. J. C., and J. M. Hall, Iron loss in titanomagnetites during low temperature oxidation, J. Geomagn. Geoelectr., 32, 661-669, 1980. 
Seyfried, W. E., Jr., Experimental and theoretical constraints on hydrothermal alteration processes at mid-ocean ridges, Annu. Rev. Earth Planet. Sci., 15, 317-335, 1987.

Soroka, W., and S. Beske-Diehl, Variations of magnetic directions within pillow basalts, Earth Planet. Sci. Lett., 69, 215-223, 1984.

Taylor, R. W., Phase equilibria in the system $\mathrm{FeO}-\mathrm{Fe}_{2} \mathrm{O}_{3}-\mathrm{TiO}_{2}$ at $1300^{\circ} \mathrm{C}$, Am. Mineral., 49, 1016-1030, 1964.

Verhoef, J., and J. Arkani-Hamed, Chemical remanent magnetization of oceanic crust, Geophys. Res. Lett., 17, 1945-1948, 1990.

Worm, H.-U., and S. K. Banerjee, Aqueous low-temperature oxidation of titanomagnetites, Geophys. Res. Lett., 11, 169-172, 1984.

Worm, H.-U., and S. K. Banerjee, The acquisition of CRM by PSD- titanomagnetite during aqueous low-temperature ozidation, XIX General Assembly of IUGG (Abstracts), 2, 490, By R.D. Russell for IUGG, Vancouver, Canada, 1987.

S. K. Banerjee and P. R. Kelso, Institute for Rock Magnetism, University of Minnesota, 251 Shepherd Laboratories, 110 Union St., S.E., Minneapolis, MN 55455.

H.-U. Wom, Federal Institute for Geosciences and Natural Resources, Außenstelle Grubenhagen, 3352 Einbeck-Rotenkirchen, Germany.

(Received March 14, 1991; revised July 8, 1991; accepted July 23, 1991.) 